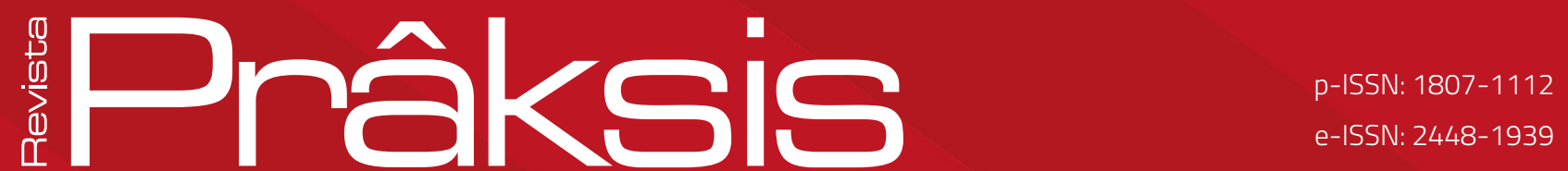

Recebido em: 02 de novembro de 2018 Aprovado em: 11 de fevereiro de 2019 Sistema de Avaliação: Double Blind Review RPR |a. 16 |n. 2 | p. 267-283 | mai./ago. 2019 DOI: https://doi.org/10.25112/rpr.v2i0.1905

\title{
FORMAÇÃO DOCENTE E AS DISCUSSÕES DE GÊNERO: (IN)VISIBILIDADES E SILÊNCIO NA FORMAÇÃO
}

\section{TEACHING TRAINING AND GENDER DISCUSSIONS: (IN)VISIBILITIES AND SILENCE IN TRAINING}

\section{Adenir Carvalho Rodrigues}

Mestre em Educação e Diversidade pela Universidade do Estado da Bahia (Salvador/Brasil).

Professor da Rede Pública Municipal e Estadual.

E-mail: adcfilos79@hotmail.com

\section{Mary Rangel}

Pós-doutora em Psicologia Social pela PUCSP (São Paulo/Brasil).

Professora na Universidade Federal do Rio de Janeiro (Rio de Janeiro/Brasil)

e na Universidade Federal Fluminense (Rio de Janeiro/Brasil).

E-mail: mary.rangel@hotmail.com

\section{Nilcelio Sacramento de Sousa}

Doutorando em Educação na Universidade Federal Fluminense (Rio de Janeiro/Brasil).

E-mail: nilceliosousa@hotmail.com 


\section{RESUMO}

A sociedade vem passando por transformações que adentram todos os espaços-tempos, exigindo que reformulações sejam realizadas nas maneiras de pensar, sentir e agir, de modo a comportar as várias nuances sociais e as diversas dicotomias em pensamentos, identidades, falares, fazeres, entre outras questões que se comprometam com a multidiversidade. Nesse pensar é que intentamos analisar como a formação continuada contribui para a discussão das questões de identidade de gênero na escola, como caminho para compreensão e quebra de estereótipos, saindo de conceitos cristalizados e ranços que fantasmagorizam nossos espaços-tempos. Os percursos teórico-metodológicos deste estudo foram sustentados na pesquisa documental e bibliográfica. Utilizamos para análise os Planos da Coordenação Pedagógica da área de Língua Portuguesa, do município de Bonito/BA. Buscamos, com essas discussões, desinvisibilizações dos conhecimentos, superação das hierarquizações e dicotomias nos temas da formação continuada, como possibilidades de vivências nos espaços praticados e partilhados por diferentes seres sociais, históricos e humanos.

Palavras-chave: Identidade de gênero. Formação continuada. Espaços-tempos formativos. Cotidiano.

\section{ABSTRACT}

Society as undergone transformations that penetrate all spacés time, demanding that reformulations be carried out in ways of thinking, feeling and acting, in order to accommodate the various social nuances and the different dichotomies in thoughts, identities, talking, doing, among others, and commit to multidiversity. In this thinking, we try to analyze how continuing education contributes to the discussion of issues of gender identity in school, as a way to understand and break stereotypes, leaving crystallized concepts and rancidities that spook our spaces. We seek with these discussions possibilities of experiences in the spaces practiced and shared by different social, historical and human beings. The theoreticalmethodological pathways of this study were supported by documental and bibliographic research. We used for analysis the Plans of Pedagogical Coordination of the area of Portuguese Language, of the city of Bonito / BA.

Keywords: Gender identity. Continuing education. Formative space. Daily. 


\section{PENSAMENTOS PROVOCATIVOS E INTRODUTÓRIOS: INICIANDO OS ESTUDOS}

Atualmente, presenciamos um conjunto de mudanças na sociedade que adentra a escola e muda sua face mais tradicional, exigindo novas posturas, tanto no que se refere aos conteúdos da aprendizagem, como na relação entre seus agentes: professor/a, aluna/o e principalmente sobre qual seria o seu papel dentro desse contexto de mudanças de paradigmas. Por isso, a invenção de novos saberfazeres ${ }^{1}$ (ALVES, 2001) se faz tão urgente e fluído ao mesmo tempo, pois não temos a garantia e nem podemos assegurar que um modelo seja o ideal (se é que um dia tivemos modelo ideal/real), para garantir o sucesso do/a educando/a dentro de uma conjuntura social de culturas que presenciam uma fluidez nunca vista antes. Nesse aspecto, nos referimos ao que Bauman (2013) denominou de mundo líquido moderno, onde "[...] a modernidade líquida é uma civilização do excesso, da redundância, do dejeto e do seu descarte" (p. 23). Sendo assim, é compreensível que o mundo o qual se conheceu não existe mais, o que era antes hoje não é mais e, dessa forma, as mudanças são repentinas e nos levarão rumo ao desconhecido, ao efêmero e ao descartável. Nesse modo de viver contemporâneo, em que as identidades são plásticas e instáveis, as relações se encontram também estremecidas. Assim, a escola precisa saber lidar com as constantes mudanças de paradigmas, sendo cobrada a dar respostas, como a única responsável por reverter o curso desenfreado da história.

Nesse sentido, partindo dessa constatação, do papel das formações continuadas docentes no trato com as questões do cotidiano escolar para além do técnico e pedagógico, é que intentamos analisar como a formação continuada contribui para a discussão das questões de identidade de gênero na escola, como caminho para compreensão e quebra de estereótipos, saindo de conceitos cristalizados e ranços que fantasmagorizam nossos espaçotempos (ALVES, 2001). Para efeitos de sentidos, adotamos aqui, o conceito de espaçostempos cunhado por Alves (2001), compreendendo-o como lugar de saber, (re) criação, (des)aprendizagens, "inteligência, imaginação, memória e solidariedade" (ALVES, 2001, p. 3), mas sobretudo como espaçotempo de possibilidades e "de grande diversidade" (ALVES, 2001, p. 3), que se entrecruzam nos atravessamentos individuais e coletivos dos diferentes sujeitos que os vivenciam/ habitam em suas multiplicidades de formas de ser e estar no/com o mundo.

Buscamos, com essas discussões, possibilidades de vivências nos espaços praticados e partilhados por diferentes seres sociais, históricos e humanos. Em razão disso, ao observar as muitas produções e abordagens no cerne acadêmico, é que surge a necessidade de dialogar acerca do tema relacionado

\footnotetext{
1"Por opção política, os estudiosos dos cotidianos no Brasil passaram a enfrentar algumas dicotomias e categorizações praticando a junção de palavras numa tentativa de capturar e criar outros sentidos menos submissos e ocidentalizados (OLIVEIRA; SÜSSEKID, 2016, p. 7).
} 
à identidade de gênero, o qual é simploriamente abordado ou não é tido como tópico relevante de discussão em espaços escolares da Educação Básica. Contudo, apesar da sua relevância no cenário educacional atual, no entanto, permanecem totalmente obscuras aos olhos dos/as formuladores/as de políticas públicas de formação continuada, atentando insistentemente para os conteúdos tradicionais de leitura e escrita e demais aspectos cognitivos da aprendizagem, esquecendo ou fazendo esquecer os aspectos relacionados às questões de identidade de gênero, étnica, religiosas entre outras/os.

Segundo Teles e Franco (2006), vale destacar que os princípios de respeitar e educar para a diversidade, em relação às diferentes formas de identidade de gênero, envolve questões multidimensionais bastante complexas de serem trabalhadas no interior das escolas. São questões multidimensionais porque abarcam discussões que vão desde a identificação das diferentes formas de preconceito até os seus respectivos impactos em relação aos grupos discriminados. Essas abordagens são complexas porque, muitas vezes, existe o preconceito em relação à própria temática no interior de muitas escolas, o que a transforma em uma das principais barreiras para o avanço da discussão nas formações e consequentemente, nas ações efetivas da escola.

Além da sua natureza, enquanto processo de aperfeiçoamento permanente, "a educação continuada se faz necessária pela própria natureza do saber e do fazer humano, como prática que se transforma constantemente" (CHRISTOV, 1998, p. 9). Por isso, a formação continuada em si é um processo contínuo de aprender em qualquer profissão. Na educação, ela se torna imperativa, uma exigência inerente ao próprio estatuto da profissão de professor/a. Com todas as mudanças sociais presenciadas na contemporaneidade, a formação continuada passa a ser encarada de forma ampla, abrangendo processos educativos que vão além da formação cognitiva do/a professor/a. Dessa forma, a formação continuada precisa acolher diversas temáticas inerentes à realidade social do presente, entre elas, a identidade de gênero latente, na grande maioria das vezes invisibilizada pela escola e por seus principais agentes, a gestão e os/as professores/as.

Assim, a teia discursiva que articula estes escritos concebe o Plano da Coordenação Pedagógica como espaçotempo (ALVES, 2001) formativo e autoformativo para analisarmos a partir das categorias teóricas: identidade de gênero, formação continuada e coordenação pedagógica com o intuito de dar maior visibilidade ao tema em questão.

Assumindo essa postura epistêmica, temos nos perguntado também sobre as estratégias das escolhas dos temas da formação continuada, bem como as subjetividades dos sujeitos formadores/as nas suas escolhas políticas/ideológicas em torno das temáticas da formação. Formação, que aparentemente, não tem interpelado às fronteiras hegemônicas definidoras dessas mesmas posturas.

Neste sentido, os percursos teórico-metodológicos deste estudo foram sustentados na pesquisa 
documental e bibliográfica. Segundo Gil (2008), "a pesquisa documental vale-se de materiais que não receberam ainda um tratamento analítico, ou que ainda podem ser reelaborados de acordo com os objetivos da pesquisa" (p. 51). Neste sentido, utilizamos para análise os Planos da Coordenação Pedagógica da área de Língua Portuguesa, do município de Bonito/BA, no Território de Identidade da Chapada Diamantina². No tocante à revisão da literatura, o trabalho se pauta na pesquisa bibliográfica; visto que ela "é um apanhado geral sobre os principais trabalhos já realizados, revestidos de importância, por serem capazes de fornecer dados atuais e relevantes relacionados com o tema" (LAKATOS; MARCONI, 2003, p. 157).

\section{FORMAÇÃO CONTINUADA, COORDENAÇÃO PEDAGÓGICA E IDENTIDADE DE GÊNERO: BREVE CONCEITUALIZAÇÃO}

A sociedade atual vive o calor da pós-modernidade com mudanças aceleradas e surgimento de novos paradigmas e a liquidez das relações e da informação. Todavia, temos consciência de que as mudanças da recente conjuntura, especificamente à educação, exigem posturas, estratégias e ações complexas, amplas e variadas. Por isso, uma das frentes de reflexão para as adaptações a estas mudanças é, sem dúvida, pensar e direcionar as formações iniciais e continuadas para contribuir com processos formativos qualificados e consistentes.

Além do movimento de reconceitualização da formação contínua, outra questão que entra em pauta refere-se às ações caracterizadas como formação continuada e os espaços onde ela ocorre, quais destes espaços são mais recomendados, tendo em vista os fins a que ela se propõe, bem como a finalidade do ato formativo enquanto dispositivo de formação e profissionalização do/a professor/a. Assim, de modos diferentes, ela se caracteriza por um conjunto de ações ou estratégias formativas compreendendo um leque de possibilidades.

Dessa forma, ela pode ocorrer no interior das escolas ou em outros espaços considerados formativos ou informativos, a depender dos fins a que se propõe envolvendo os processos educativos. Sendo assim, Libâneo (2013) classificam-na em: as que ocorrem fora da escola por meio de cursos, congressos, seminários, colóquios, jornadas de educação, grupos de estudos e pesquisa, etc; e as que ocorrem no universo da escola, como as participações no projeto pedagógico da escola, entrevistas e reuniões de

\footnotetext{
2 O Território de Identidade da Chapada Diamantina, Região da Chapada, está localizado no centro do estado da Bahia, distante da capital baiana 427 km. Compreendendo 23 municípios (Abaíra, Andaraí, Barra da Estiva, Boninal, Bonito, Ibicoara, Ibitiara, Iraquara, Tietê, Jussiape, Lençóis, Marcionílio Souza, Morro do Chapéu, Mucugê, Nova Redenção, Novo Horizonte, Palmeiras, Piatã, Rio de Contas, Seabra, Souto Soares, Utinga e Wagner), com uma área total de $30.458,88 \mathrm{Km} 2$.
} 
orientações, grupos de estudos, seminários internos, reuniões de trabalho para discutir a prática com colegas, pesquisa, minicursos de atualização, estudos de caso, conselho de classe, programa de educação à distância, etc.

Canário (2006) entende que a formação centrada na escola não é a mera transferência das ações tradicionais de formação para o espaço físico da escola. Antes são necessárias outras concepções que façam da formação uma oportunidade coletiva de aprendizagem. Assim, deve-se ter em mente estratégias para que a formação centrada na escola possibilite o desenvolvimento de competências profissionais adequada aos novos contextos educativos.

Nesse sentido, além dos aspectos ligados ao ser professor/a, outra questão precisa ser colocada em pauta no processo de formação contínua: o estudo de temas que se relacionam à identidade de gênero, aos conflitos étnicos, religioso e tantos/as outros/as ligados/as à diversidade cultural; pois, na atual conjuntura não se pode pensar em educação e escola restringindo-se apenas aos aspectos cognitivos do ato de ensinar e aprender. Neste caso, como afirma Rangel e Freire (2011), a formação docente deve estar alicerçada em uma prática que possibilite a democratização plural do conhecimento, através de uma posição crítica, reflexiva e transformadora, de forma individual e também coletiva, na busca da garantia dos direitos de todos os indivíduos.

Nesse processo, compreendemos a formação continuada como uma dimensão ampla do processo de aprender do professor, indo muito além do aprender os aspectos práticos da tarefa de ensinar. Ela lida com elementos da profissionalização do professor que compreende aspectos técnicos, metodológicos, axiológicos e políticos da profissão, os quais vão se constituindo ao longo da profissão, ou seja, uma formação docente entendida como espaço-tempo(idem) de partilhas coletivas, "[...] afetos, deslocamentos, conversas, diálogos, (des)aprendizagens (SAMPAIO; RIBEIRO, 2005, p. 114) nas conversas tecidas criticamente "[...] sobre a prática e reconstrução permanente da identidade pessoal e profissional [...]" (NÓVOA, 2002, p. 390).

Nessa direção, Mello (2004, p. 113) considera que "os sujeitos constroem tanto conhecimentos acerca de diferentes objetos quanto representações, conceitos e valores sobre o papel da escola, do professor e da relação ensino-aprendizagem". Nesses aspectos, a formação se dá num processo dialético entre o ser do professor e o seu fazer, no qual, ao longo do tempo, vai tomando consciência dos processos que envolvem a sua profissão e todas as demais dimensões que são abrangidas pela cultura escolar atentando para os aspectos sociais, econômicos e principalmente políticos. 
Dentro deste contexto, a atuação do/a coordenador/a pedagógico/a é imprescindivel, dado a sua importância no trabalho que desempenha nas unidades escolares. Principalmente, tendo como uma das principais atribuições da sua atuação, a formação continuada dos/as professores/as e a função de coordenar e articular os vários segmentos dentro da escola. Deste modo, estes profissionais, como os responsáveis pelas formações dos docentes precisam estudar para dar conta das novas e complexas exigências e temáticas que o cotidiano escolar os impõe.

Como anteriormente mencionamos, o/a coordenador/a pedagógico/a é um profissional que diante da formação continuada tem importância redobrada. Já que, diante das mudanças sociais aceleradas, que tem levado à escola um conjunto de novas exigências no campo da gestão das aulas, da administração, dos processos pedagógicos e da coordenação das ações educativas como um todo. Desta forma, sua atuação profissional é imprescindivel para intermediar todo esse processo.

Entre tantas outras funções da coordenação pedagógica, acrescenta-se a ela, a direção e a mediação tanto para a construção coletiva do currículo como para a efetivação do mesmo. Aqui também se diz que profissional se pretende ter, quais desafios precisam vencer e quais processos de formação e desenvolvimento profissional pretende fomentar e garantir, tanto para os professores, como para o próprio coordenador e também para os demais profissionais da educação. Daí a importância da coordenação, pois:

Pressupõe, portanto, uma disponibilidade para transitar entre diferentes cenários e espaços, encontrando projetos diversos (às vezes antagônicos), construindo caminhos de aproximação, negociação, diálogo e troca, entendendo os constituintes do grupo coordenado como pares legítimos institucionalmente e partícipes de um dado projeto político-pedagógico (BATISTA, 2001, p. 110).

Dessa forma, o coordenador é visto como um agente que poderá ou não, impulsionar o processo de mudanças na escola, nas práticas das/os professoras/es e quem sabe nas práticas sociais mais amplas. A coordenação pedagógica precisa saber transitar entre os diferentes espaços, mediando o diálogo entre seus pares e para isso precisa desenvolver algumas ações/atitudes que precisam ser contempladas tanto no processo de formação continuada como em outras ações dentro do contexto escolar. Refletindo com Rangel (2001) para que o coordenador pedagógico seja o elo que (des)tece as transformações didáticas-pedagógicas e sociais, é necessário que busquem constantemente saberes e conhecimentos concernentes às várias formas de (re)construir conhecimento e metodologias, desenvolvendo assim um (des)conhecimento contextualizado e sistematizado elaborado em uma permanente dinâmica interativa entre reflexão e ação. 
Entre esta temática discutimos aqui a ausência da categoria identidade de gênero nos Planos de Formação Continuada da Coordenação Pedagógica. Mas antes, faz-se necessário conceituarmos esta categoria, pouco entendida e por vezes confundida por parte dos/as professores/as e da sociedade em geral.

Conforme Louro (2003) gênero se refere "[...] ao modo como as características sexuais são compreendidas e representadas ou, então, como são trazidas para a prática social e tornadas parte do processo histórico" (p. 26). Dessa forma, podemos afirmar que, gênero é o modo como as características femininas e masculinas são entendidas e construídas em uma cultura; são as formas como a sociedade determina maneiras distintas de viver para as pessoas segundo seu sexo biológico, ou seja, é o que se espera de homens e mulheres, os modos como as expectativas, jogos de papéis e funções, histórica e culturalmente delimitadas, o modo como as pessoas se relacionam com essas ideias, crenças e conceitos, isto é, as relações de gênero, estão presentes em todas as relações sociais e a escola não escapa dessas discussões e construções simbólicas e mediáticas. Estas práticas e instituições "fabricam" os sujeitos. Por outro lado, Silva (1999) afirma que: "nós somos o que nossa suposta identidade define que somos" (p. 107).

Sob esse prisma, compreendemos que os seres humanos podem exercer sua sexualidade de diferentes formas, eles/elas podem vivenciar seus desejos e prazeres de muitos modos. Suas identidades sexuais se constituem através das formas como vivem sua sexualidade, com parceiros/as do mesmo sexo, do sexo oposto, de ambos os sexos ou sem parceiros/as. Do mesmo modo, os sujeitos também se identificam, social e historicamente, como masculinos ou femininos e assim constroem suas identidades de gênero.

Por isso, a formação continuada compreendida como espaço-tempo (ALVES, 2001) provocativo de (re) construção de saberfazeres (idem), lugar este, entendido por Certeau (1994) como o espaço praticado e partilhado pelas pessoas, precisa desenformar os modelos e olhares que se tem em relação aos sentidos que os/as docentes trazem sobre as relações de gênero ao invés de rotular e enquadrar as crianças, seus comportamentos e resistências, já que os "[...] processos de formação se desenham na trajetória e pela ação dos sujeitos em múltiplos contextos com os quais se tecem experiências e sentidos para fazer-se professor e fazer as escolas (e com as escolas) cotidianamente" (SÜSSEKIND; HELAL, 2012, p. 4).

É nessa perseguição de perceber a formação continuada como espaço-tempos (idem) de criação e recriação, e a partir da constituição conceitual da identidade de gênero, que partimos para a análise dos Planos de Formação da Coordenação, buscando perceber que espaço ocupa as discussões de gêneros nesses percursos formativos. 


\section{3 (DES)VELANDO O PLANO DE FORMAÇÃO DOCENTE SOBRE AS QUESTÕES RELACIONADAS À IDENTIDADE DE GÊNERO}

A análise dos Planos de Formação das Coordenadoras Pedagógicas constituiu parte importante das inferências e interpretações do tema em questão, justamente por ser um instrumento de direcionamento das formações continuadas e demais orientações pedagógicas desenvolvidas por elas/eles na escola com suas/seus professoras/es. Neste trabalho elegemos o Plano de Formação de Língua Portuguesa, já que a coordenação é específica por áreas. Além do mais, este componente curricular compreende um número maior de aulas, além de possibilitar e contemplar uma gama diversa de leituras e gêneros textuais, podendo ou não contemplar as questões relacionadas à leitura de mundo, às questões de diversidade, entre elas identidade de gênero, entre tantos/as outros/as.

O Plano de formação foi analisado a partir do Portfólio sobre o qual a coordenadora o apresenta como sendo uma "pequena coleção de registros de trabalhos significativos das/os professoras/es" (PORTFÓLIO, 2015, p. 1). Nele, o Plano é apresentado trazendo a função da coordenação, mesmo que de forma implícita, o conceito e os conteúdos das formações, o conceito de planejamento e da avaliação defendida, além da função do documento, nesse caso, do próprio portfólio, que registra e documenta o percurso formativo ocorrido durante o ano letivo de 2015.

As pistas encontradas no material nos permitem perceber as propostas de formação das coordenações pedagógicas pensadaspraticadas (OLIVEIRA, 2012, apud SÜSSEKIND, 2015)nessa pesquisa como espaços formativos que não possibilitam discussões a respeito das temáticas das relações de gênero, nos levando a inferir que o espaço da escola torna-se, assim, um dos locus mais difíceis no enfrentamento de preconceitos de gênero, pois "[...]é nela que se encontra grande parte dos padrões de comportamentos femininos e masculinos, tornando assim a convivência mais difícil para os homossexuais que são ridicularizados, excluídos dos grupos" (LOURO, 1997, p. 33). Assim, nesse espaço-tempo (ALVES, 2001) formativo como na escola, na grande maioria das vezes, as questões das identidades de gênero são excluídas, ridicularizadas e muitas vezes sofrem agressões físicas por suas orientações de gênero, contribuindo assim para que os/as discentes (re)construam a respeito de si mesmo "[...] impressões equivocadas, imaginárias do real [...]" (RANGEL, 2013, p. 23) ao mesmo tempo em que queiram se encaixar em "[...] modelos preconcebidos e idealizados de comportamentos, que podem influir, inclusive, na forma como cada sujeito se apresenta diante dos demais [...]" (RANGEL, 2013, p. 23), colocando em xeque a convivência respeitosa e o reconhecimento humano, social e político das diferenças.

As reuniões realizadas semanalmente são os momentos em que acontecem a formação continuada, além da reflexão sobre a prática, planejam-se as demais ações pedagógicas. Nesse sentido, as práticas 
formativas ocorrem semanalmente com duração de quatro horas/aulas. Elas contribuem também para pensarem as intervenções pedagógicas para sanar as dificuldades encontradas no dia-a-dia da escola. Portanto, nas reuniões pedagógicas tratam-se da tematização da prática e das intervenções pedagógicas, como os planos de ensino e os projetos pedagógicos, os diagnósticos de leitura e escrita e o plano de ação da escola, entre outros.

Nas reuniões pedagógicas, o planejamento é o ponto central, ocupando parte significativa da função da coordenação na escola com os professores. No Plano, a concepção de planejamento está explícita quando afirma: "O planejamento é um instrumento indispensável para ação pedagógica, já que, de outro modo, seria impossível orientar o processo até os propósitos perseguidos" (PORTFÓLIO, 2015, p. 4).

Como o planejamento é o cerne das formações e do que se vai trabalhar nas aulas durante as unidades letivas, nos detemos a observar a sua estrutura e os conteúdos das suas pautas, onde percebemos que estas trazem como conteúdo da formação o prosseguimento do que fora iniciado na jornada pedagógica do início e do meio do ano.

Dessa forma, as pautas dos planejamentos têm a seguinte estrutura organizacional: primeiro trazem o tema a ser discutido, sobre o qual realizam o planejamento; o propósito, que é o objetivo geral; as aprendizagens esperadas, que correspondem aos objetivos específicos e dizem respeito ao que se espera que os/as professores/as aprendam à partir da formação; os conteúdos da formação; a justificativa, em que menciona o aporte teórico da formação; os dispositivos de formação, que são os momentos da formação, a partir do qual as ações vão se realizando, utilizando, para isso, o material necessário. Seguem, então, com o detalhamento da pauta, que na verdade, são os procedimentos metodológicos realizados para executar a formação, divididos nos vários momentos didáticos, e por último traz as referências utilizadas.

Pela estrutura e organização didática dos planejamentos, dos conteúdos utilizados e dos dispositivos de formação, deduz-se que ao final de cada planejamento tenham realizado uma profícua reflexão da prática, por meio de fundamentos teóricos, da produção de instrumentos de ensino e de intervenções pedagógicas, além de reflexões sobre a realidade da escola. Assim, elencamos as ações que foram utilizadas nas formações dentro dos espaços de planejamentos semanais do ano de 2015 :

Formação do professor leitor; Conhecendo o ambiente escolar; Estudo do material teórico; Elaboração de projeto didático de leitura; Elaboração de projeto didático de leitura com foco nos indicadores e Instrumentos de avaliação; Organizando os momentos das modalidades organizativas; Tematização da prática; Elaboração de sequência didática de ortografia; Analise do resultado do diagnóstico de leitura; Planificação dos conteúdos da I unidade; Discussão sobre resultado do diagnóstico de leitura; Elaboração do Plano de Ação - ação do professor e coordenador; Analise do resultado da escrita dos alunos; Dupla conceitualização (coloca o professor no lugar do aluno, ou seja, simula 
uma atividade que ele passaria para o aluno e ele vai resolvê-la como se fosse o aluno para identificar as principais dificuldades da atividade); Escrita profissional (PORTFÓLIO, 2015, p. 16-34).

Como podemos observar, os planejamentos semanais seguem preconizando as elaborações de sequências didáticas, no caso de Língua Portuguesa, com o propósito de que os/as alunos/as desenvolvam a leitura e a escrita, para isso as sequências trazem gêneros textuais como a fábula, contos de terror, entre outros. Nesse sentido, há uma preocupação e um investimento muito grande nas intervenções didáticas voltadas para a leitura e para a escrita. Os desafios apresentados e discutidos nestes espaços estão sempre relacionados com estes dois conteúdos, os demais conteúdos, como as questões dos valores, da identidade dos estudantes e das relações e interações sociais no ambiente escolar não são, em momento nenhum, mencionados nos conteúdos das pautas de formação continuada e dos planejamentos semanais.

Da mesma forma, o conteúdo da formação das coordenadoras realizada pela supervisora técnica responsável pela formação da coordenação de Língua Portuguesa e demais coordenadoras demonstra o que temos tratado acerca da ausência dos temas da diversidade e identidade de gênero nos conteúdos de formação continuada.

Sobre os mesmos, assim relatou a supervisora técnica do ensino Fundamental II:

Supervisora técnica FII: Participar da elaboração do plano de formação e de sua constante atualização, face aos contextos e conjunturas sociais, culturais e pedagógicas do município, das escolas e dos educandos.

Organizar o acervo e a memória da formação continuada municipal dos coordenadores pedagógicos e professores por meio da criação e manutenção de um acervo público de pautas de formação, relatórios dos encontros formativos, vídeos de observação de sala de aula, gráficos com os resultados da aprendizagem e outros documentos produzidos no seu dia a dia.

Dialogar com o diretor pedagógico sobre as condições pedagógicas e estruturais necessárias para a atuação do coordenador pedagógico e dos professores, favorecendo ações conjuntas e proativas da equipe técnica municipal.

Favorecer a integração das escolas municipais da rede, fomentando a troca e socializando as boas práticas.

Apoiar o coordenador pedagógico no planejamento e na organização dos encontros formativos que ele realiza na escola e no acompanhamento das práticas de ensino, com vistas a melhorar as condições de ensino dos professores e as de aprendizagem dos alunos.

Como sabemos, a formação é sempre um processo social que implica um confronto de pontos de vista 
entre o polo dos formadores, dos formandos e do município, o qual é o responsável maior pela gestão destas formações. Daí a necessidade da lógica da problematização das situações reais que atravessam os cotidianos das escolas, feitas em contextos variados pelos vários atores no processo formativo. Desta forma, nesta lógica pode-se constituir a chave para o desenvolvimento de modalidades de formação centrada na escola e nas necessidades dos seus atores.

O Plano defende a concepção que, a meta da educação é criar seres humanos que sejam capazes de fazer coisas novas, ser criadores, inventores e descobridores. Nesse sentido, para que a escola cumpra com essa meta, são realizadas práticas avaliativas, que cumprem com estes propósitos, uma vez, que realizam diagnóstico inicial de leitura com dados essenciais de que precisam. Após terem as informações de que precisam, qualificam-nas e apresentam as/os professoras/es para elaborarem um trabalho refletido, consciente do momento cognitivo em que o aprendiz se encontra.

Apesar de o Plano apresentar como meta da educação a criação de um ser humano, livre, consciente, criativo e, portanto, feliz. No decorrer das análises, não percebemos nenhuma indicação no Plano de Formação e respectivas pautas de planejamento destas formações, discussão que trouxesse para o centro outros elementos temáticos que discutam as questões e dilemas presentes na escola como: a diversidade cultural, questões axiológicas e da identidade de gênero em específico. Neste sentido, podemos nos perguntar que ser humano é este que a escola pretende formar, onde seus aspectos ontológicos mais essenciais não são mencionados?

O que podemos perceber foi uma preocupação geral do currículo de formação continuada docente baseada exclusivamente nos aspectos cognitivos de aprendizagem da leitura e da escrita, negligenciando os temas da proposta pós-crítica de currículo no contexto atual (SILVA, 1999; LOPES; MACEDO, 2011; MACEDO, 2006; PARAíSO; CALDEIRA, 2018). Como nos aponta Silva (1999), que vê também no currículo uma narrativa étnica e racial, reafirmando uma superação, ampliação do pensamento curricular crítico que aponta a dinâmica de classe como única no processo de reprodução das desigualdades sociais. Estes autores alertam para a abertura de discussões outras, como as questões relacionadas a etnia, raça e gênero, configurando um novo repertório educacional significativo.

Entendemos, nesse ínterim, que a lógica de um currículo cartesiano não dá conta de estar diante da complexidade da formação continuada para a atual sociedade, pois questões relativas à diversidade, identidade de gênero, como tantas outras relegadas ao segundo plano nos currículos escriturários, só recentementeestãosendoproblematizadas, apartir deanálisespós-estruturalistasedosestudosculturais, "é através do vínculo entre conhecimento, identidade e poder que os temas da raça e da etnia ganham seu lugar no território curricular" (SILVA, 1999, p. 101). 
Nossos estudos nos direcionam a pensar, que só depois de conhecer as teorias críticas e pós-críticas, torna-se impossivel conceber a formação continuada e o currículo dessa formação de forma ingênua e desvinculada de relações sociais de poder. Para as teorias críticas isso significa nunca esquecer, por exemplo, a determinação econômica, a busca de liberdade e emancipação; e para as pós-críticas significa questionar e/ou ampliar muito daquilo que a modernidade nos legou.

Assim, o que se percebeu/viveu/sentiu ao analisar os Planos de Formação da Coordenação Pedagógica, foi um apreço demasiado por elementos mais tradicionais do currículo, invisibilizando as demais dimensões do sujeito que aprende como sua identidade, os dilemas étnicos e principalmente da identidade de gênero, o objetivo deste trabalho. O currículo é capaz de configurar em que plano simbólico, cultural e político estão representados os processos formativos; pois como nos assinala Caetano (2013) é através dos "[...] currículos prescritos e/ou praticados" (p. 4) que as formações continuadas "[...] ganham importância por ser um dos dispositivos pelos os quais a escola executa a formação de seus sujeitos" (CAETANO, 2013, p. 4.).

Nesse sentido, precisamos de um renovado entendimento da experiência pessoal e social dos saberes do senso comum para a superação da linearidade "[...], da hierarquia dos epistemicídios e das monoculturas pela ecologia de saberes" (SÜSSEKIND, 2012, p. 618). Isso implica, também, compreender que embora haja currículos oficiais, há múltiplos currículos em ação nos diversos espaço-tempos.

\section{DIMENSÕES METODOLÓGICAS DA PESQUISA: DOCUMENTAL E BIBLIOGRÁFICA}

No que se refere aos objetos de estudo, a pesquisa educacional tem suas singularidades, principalmente porque, na sua grande maioria, elas não são passíveis de quantificações, como os objetos das ciências físicas e da matemática. Mas ao contrário, a educação como ciência social mantém contato direto com pessoas, que se tornam participantes dos processos investigativos. Nesse caso, os sujeitos da pesquisa são professoras/es, coordenadoras/esesupervisoras/estécnicas/os, estesúltimosparticipamdadiscussão, na medida em que supervisionam os planos de formação da coordenação. Todos estes sujeitos participam ativamentecomsuas experiências, valores, representações, históriaesaberes, portanto comseusuniversos subjetivos.

Assim, segundo Ludké (2013), é fato que na atualidade

Cada vez mais se entende o fenômeno educacional como situado dentro de um contexto social, por sua vez, inserido em uma realidade histórica, que sofre toda uma série de determinações. Um dos desafios atualmente lançados à pesquisa educacional é exatamente o de tentar captar essa realidade dinâmica e complexa do seu objeto de 
estudo, em sua realização histórica (LÜDKE; ANDRÉ, 2013, p. 6)

Como podemos ver, a pesquisa educacional é revestida de alto grau de complexidade por estar inserida dentro de uma realidade dinâmica e histórica. Sendo assim, é fácil percebermos que a escolha dos pressupostos metodológicos levou em consideração todas essas especificidades próprias do universo das Ciências Sociais. Portanto, para que a realidade estudada pudesse ser da melhor forma compreendida, apresentamos de forma sucinta os passos dados para alcançarmos o objetivo deste estudo.

Para Chizzotti (1995, p. 11), "[...] a pesquisa investiga o mundo em que [...]" o ser humano vive e o próprio ser humano. Por isso, afirmamos que, a pesquisa é um diálogo crítico e criativo com a realidade, culminando com a elaboração própria e com a capacidade de intervenção. Em suma, pesquisa é a atitude de "aprender a aprender", e, como tal, faz parte de todo processo educativo e emancipatório (Demo, 2001). Mas para isso, é preciso o apoio de procedimentos metodológicos adequados, que permitam a aproximação ao objeto de estudo e suas dimensões fenomênicas. Por isso, partindo dessa concepção a pesquisa em tela, desenvolveu-se mediante o percurso teórico-metodológico da pesquisa documental e bibliográfica possibilitando ao/a pesquisador/a a (des)cobertura de uma "[...] gama de fenômenos muito mais amplos do que aquela que poderia pesquisar diretamente" (idem, p. 45).

Análise documental, inspirado em Lakatos e Marconi (2003), foi analisada aqui a documentação indireta, formando o conjunto de fontes de informação por meio dos documentos produzidos no município, os quais formaram o conjunto dos planos de formação continuada e os referenciais teóricos que embasam os referido planos. No tocante a pesquisa bibliográfica, usamos fontes secundárias como livros, teses e artigos. A análise e interlocução com as categorias defendidas pelos autores embasados deram o lastro de sustentação à discussão e os resultados obtidos foram frutos de tal processo, demonstrando a validade da escolha metodológica.

\section{CONSIDERAÇÕES FINAIS}

A formação continuada, entendida como espaço-tempo (ALVES, 2001) formativo, precisa ir além dos aspectos da leitura e da escrita, e compreender o espaço escolar como múltiplo, complexo, marcado e atravessado pelas relações de gênero que determina por vezes quem fala e quem deve se calar, quem deve ser visto e quem deve ser ocultado, amordaçados e silenciados num processo de violência simbólica e histórica, que ainda permanece quase que inalterada. Precisamos estar atentos para que sejamos capazes de ver, ouvir, sentir as múltiplas formas de constituição dos sujeitos implicadas na concepção, na organização e no fazer cotidiano escolar, já que a "arte de fazer", como nos diz Certeau (1994), é a 
constante movimentação de (re)invenção do cotidiano, já que as ações cotidianas, na sua multiplicidade de formas de realização, não são e não podem ser repetidas no seu como fazer.

Os Planos de Formação precisam contemplar as temáticas que entrelaçam as relações de poder, que procuram invisibilizar uns e empoderar outros, num processo desigual e injusto como tem ocorrido com as relações de gênero na escola. Precisamos nos abrir para o novo, para o diferente e desnaturalizar nosso olhar para percorrermos as paredes, os corredores e salas, deter-se nas pessoas, nos seus gestos, suas roupas; é preciso perceber os sons, as falas, as sinetas e os silêncios; é necessário sentir os cheiros especiais; as cadências e os ritmos marcando os movimentos de adultos e crianças.

Observamos, contudo, que o processo de formação continuada contribui para o aperfeiçoamento profissional docente, nos aspectos técnicos pedagógicos, mas não consegue discutir outros aspectos como o papel da escola na formação de valores e do respeito à diversidade sexual presente na escola, a qual é invisibilizada pela escola e por seus agentes, reforçado por meio de suas práticas e ações para a exclusão e negação de direitos dos sujeitos que não se encaixam dentro dos padrões da heteronormatividade, perpetuando com isso, invisibilidades, ignorância, falta de conhecimento, preconceito e estereótipos vários, não contribuindo, dessa forma, para percebemos que "[...] existem tantas sexualidades quanto existem sujeitos no mundo, existem tantos currículos praticados sobre sexualidade quanto professores e professoras no mundo" (CAETANO, 2013, p. 14 .).

Assim, ao longo da trajetória investigada, entre percepções e assumindo uma postura epistêmica, nos perguntando também sobre as estratégias das escolhas dos temas da formação continuada, bem como as subjetividades dos sujeitos formadores/as nas suas escolhas políticas/ideológicas em torno das temáticas da formação.

Portanto, a formação, aparentemente não tem interpelado às fronteiras hegemônicas definidoras dessas mesmas posturas e não tem contribuindo para emancipação social, pois se torna cada vez mais evidente a necessidade de pensar a formação que "[...] emerge como socialmente relevante na medida que é o espaço-tempo da realidade social, portanto onde essa ocorre, se modifica, inventa, seus modos de fazer, suas possibilidades de mudança" (OLIVEIRA; SGARBI, 2008, p. 85).

\section{REFERÊNCIAS}

ALVES, N; OLIVEIRA, I. B. Pesquisa nos/dos/com os cotidianos das escolas: sobre redes de saberes. 3. ed. Petrópolis: DP et Alii,2001, p. p 15-38. 
BATISTA, Sylvia H. S. da Silva. Coordenar, avaliar, formar: discutindo conjugações possíveis. In: ALMEIDA, L. Ramalho. PLACCO, Vera Maria N. de Souza. $\mathbf{O}$ coordenador pedagógico e o espaço da mudança. São Paulo: Loyola, 2001.

BAUMAN, Zygmunt. Tempos líquidos. Rio de Janeiro, RJ: Jorge Zahar Editor Ltda, 2013.

CANÁRIO, Rui. A escola tem futuro? Das promessas as incertezas. Porto Alegre: Artmed, 2006.

CAETANO, Márcio. Currículos praticados e a construção da heteronormatividade. In: ALEXSANDRO, Rodrigues; CORRÊA, Barreto Maria Aparecida Santos. (Org.). Currículos, gêneros e sexualidades: experiências misturadas e compartilhadas. Vitória/ES: Edufes, 2013.

CERTEAU, M. A invenção do cotidiano. 1. Artes de fazer. Petrópolis: Vozes, 1994.

CHIZZOTTI, Antonio. Pesquisa em ciências humanas e sociais. São Paulo: Cortez, 1995

CHRISTOV, L. H. S. Educação continuada: função essencial do coordenador pedagógico. In: Guimarães A.A et al. 0 coordenador pedagógico e a educação continuada. São Paulo: Loyola, 1998.

DEMO, Pedro. Saber pensar. 2 ed. São Paulo: Cortez, 2001.

GIL, Antônio Carlos. Métodos e técnicas de pesquisa social. 6. Ed. São Paulo: Atlas, 2008.

LAKATOS, Maria Eva; MARCONI, Maria de Andrade. Fundamentos de metodologia científica. 5. ed. São Paulo. Revista e Ampliada. Atlas, 2003.

LOPES, Alice Casimiro; MACEDO, Elizabeth. Teorias de currículo. São Paulo: Cortez, 2011.

LOURO, Guacira Lopes. Gênero, sexualidade e educação: Uma perspectiva pós- estruturalista Vozes. Rio de Janeiro. 1997.

(Org.) 0 corpo educado: pedagogia da sexualidade. Petrópolis: Vozes, 2003.

LÜDKE, Menga; ANDRÉ, Marli E. D. A. Pesquisa em Educação: abordagens qualitativas. 2 ed. São Paulo: EPU, 2013.

MACEDO, Elizabeth (2006). Currículo: Cultura, política e poder. In: Currículo sem Fronteiras, v. 6, n. 2, p. 98-113, jul./dez. 2006.

MELLO, Guiomar Namo de. Educação escolar brasileira: o que trouxemos do século XX? Porto Alegre: Artmed, 2004. 
NÓVOA, Antônio. Formação de professores e trabalho pedagógico. Lisboa: Educa, 2002.

OLIVEIRA, Inês Barbosa de; SGARBI, Paulo. Estudos do Cotidiano \& Educação. BH: Autêntica, 2008.

. I. Barbosa e SÜSSEKIND V. M. L. Formação docente e justiça cognitiva: pesquisa, práticas e possibilidades. ed. Rio de Janeiro: DP et Alii, 2016.

PARAIISO, Marlucy Alves; CALDEIRA, MARIA CAROLINA. (Org.). Pesquisas sobre currículos, gêneros e sexualidades. Belo Horizontes: Mozza Edições, 2018.

PORTFÓLIO DE LINGUAGEM. Plano de formação de Língua Portuguesa. Bonito/BA. 2015.

RANGEL, Mary. Supervisão pedagógica: princípios e práticas. Campinas: Papirus, 2001.

. FREIRE, Wendel (Org.). Supervisão escolar: avanços de conceitos e processos. Rio de Janeiro: Wak, 2011.

. Diversidade e seus efeitos na autorrepresentação. In: RANGEL, Mary. (Org.). A escola diante da diversidade. Rio de Janeiro: Wark Editara, 2013.

SAMPAIO, Carmem Sanches; RIBEIRO, Tiago. Documentação narrativa de experiências pedagógicas: escritas de si e formação docente. In: SOUZA, Clementino de. (Org.). (Auto)biografias e documentos narrativos: redes de pesquisa e formação. Salvador: Edufba, 2015, p. 105-125.

SILVA, Tomaz Tadeu da. Documentos de identidade: uma introdução às teorias do currículo. Belo Horizonte: Autêntica, 1999.

SÜSSEKIND, Maria Luiza. 0 ineditismo dos estudos nosdoscom os cotidianos: currículos e formação de professores, relatos e conversas em uma escola pública do município do Rio de Janeiro, Brasil. In: Ecurriculum, São Paulo, v. 8, n. 2, ago. 2012.

; HELEL, Igor. Dez dias e além! o estágio supervisionado como entrelugar e

possibilidades de formação: experiências e estéticas no fazer com a escola básica. In: XVI ENDIPE Encontro Nacional de Didática e Práticas de Ensino - UNICAMP - Campinas - 2012.

TELES, J. Luiz e FRANCO, Cláudia T. Signorio. Educação na diversidade: como indicar as diferenças? Brasília: Secretaria de Educação Continuada, Alfabetização e Diversidade, 2006. 